\title{
Modeling forest evapotranspiration and water balance at stand and catchment scales: a spatial approach.
}

\author{
Samuli Launiainen ${ }^{1}$, Mingfu Guan ${ }^{2,1}$, Aura Salmivaara ${ }^{1}$, and Antti-Jussi Kieloaho ${ }^{1}$ \\ ${ }^{1}$ Nature Resources Institute Finland, Latokartanonkaari 9, 00790 Helsinki, Finland \\ ${ }^{2}$ Department of Civil Engineering, The University of Hong Kong, HKSAR, China \\ Correspondence: Samuli Launiainen (samuli.launiainen@luke.fi)
}

Copyright statement. Author(s) 2019. CC-BY 4.0 License

\section{Supplementary material}

\section{Supplementary figures and tables}

Supplementary material is provided below to support interpretation of the manuscript.

For details how to set up and run the model, please see the model code and brief user manual at https://github.com/ lukeecomod/spafhy_v1.

The figures and tables are referred as Fig. or Table Sx in the main paper 


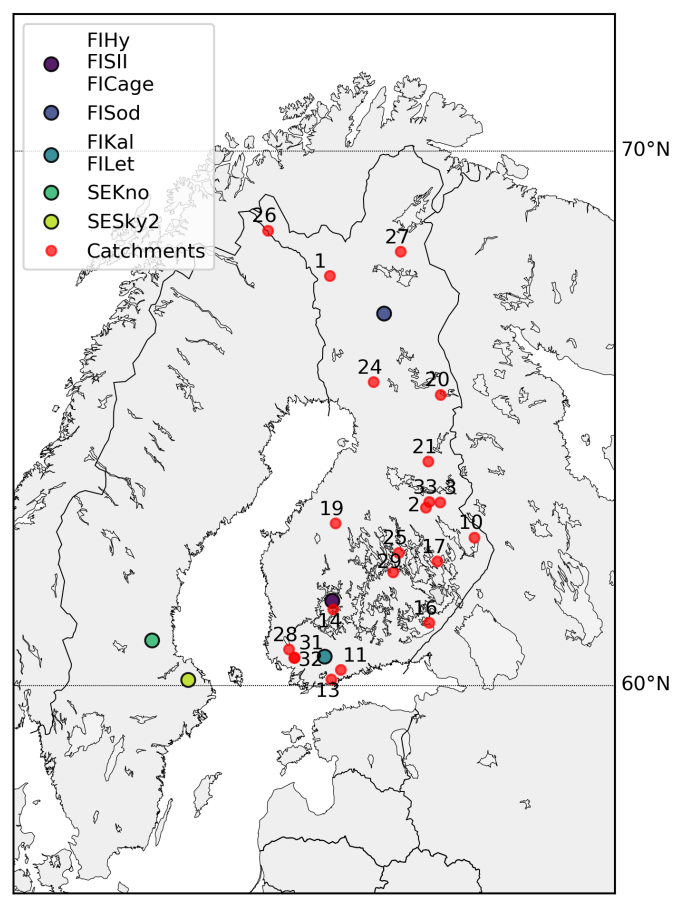

Figure 1. Location of the eddy-covariance sites (Table 1) and the 21 headwater catchments (Table S1) used in this study. 

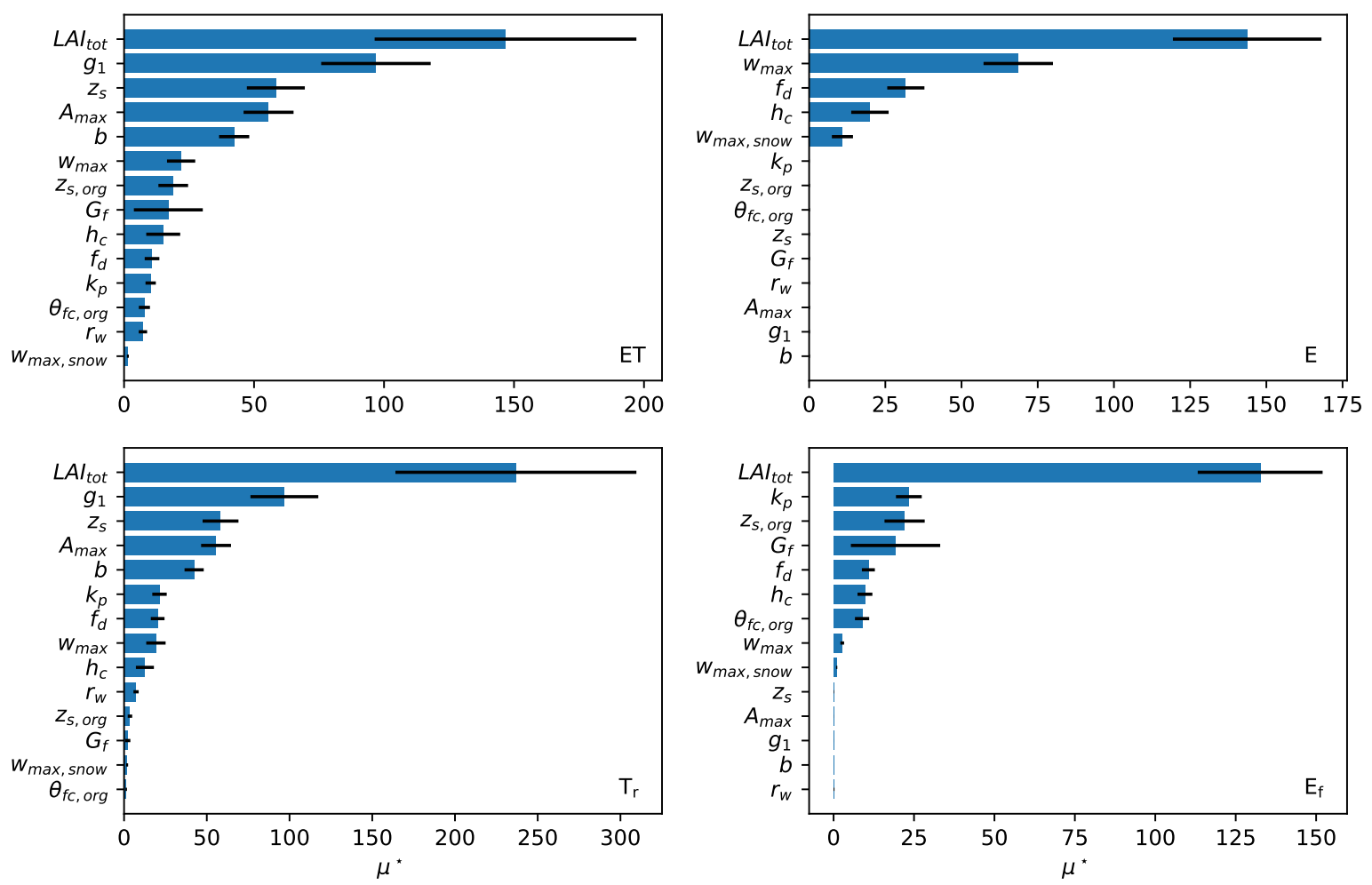

Figure 2. Parameter ranking based on mean of absolute values $\left(\mu_{\star}\right)$ of the distribution of elementary effects for evapotranspiration (ET), transpiration $\left(T_{r}\right)$, evaporation from canopy interception $(E)$, and ground evaporation $\left(E_{f}\right)$. The higher the $\mu_{\star}$ the more influential the parameter is. Error bars are 95\% confidence intervals based on re-sampling $(\mathrm{N}=1000)$. 
Table 1. Soil types and their hydraulic properties used in the simulations. The $\theta_{s}$ is porosity, $\theta_{f c}$ and $\theta_{w p}$ volumetric water contents at field capacity and wilting point, $K_{\text {sat }}$ saturated hydraulic conductivity and $\beta$ parameter describing power-law decay of hydraulic conductivity with decreasing saturation ratio.

\begin{tabular}{lccccc}
\hline Type & $\begin{array}{c}\theta_{s} \\
\left(\mathrm{~m}^{3} \mathrm{~m}^{-3}\right)\end{array}$ & $\begin{array}{c}\theta_{f c} \\
\left(\mathrm{~m}^{3} \mathrm{~m}^{-3}\right)\end{array}$ & $\begin{array}{c}\theta_{w p} \\
\left(\mathrm{~m}^{3} \mathrm{~m}^{-3}\right)\end{array}$ & $K_{\text {sat }}\left(\mathrm{m} \mathrm{s}^{-1}\right)$ & $\beta(-)$ \\
\hline Coarse textured & 0.41 & 0.21 & 0.10 & $1.0 \times 10^{-4}$ & 3.1 \\
Medium textured & 0.43 & 0.33 & 0.13 & $1.0 \times 10^{-5}$ & 4.7 \\
Fine textured & 0.50 & 0.34 & 0.25 & $1.0 \times 10^{-6}$ & 7.9 \\
Peat & 0.90 & 0.41 & 0.11 & $5.0 \times 10^{-5}$ & 6.0 \\
\hline
\end{tabular}

Coarse textured includes sand, sandy till and gravelly till soils. Medium textured cover soil types from fine finesand and silty tills to finesandy till. Fine textured represents clays and silt. Hydrological properties correspond to sand, and silty loam and clay in Bittelli et al. (2015), respectively. 


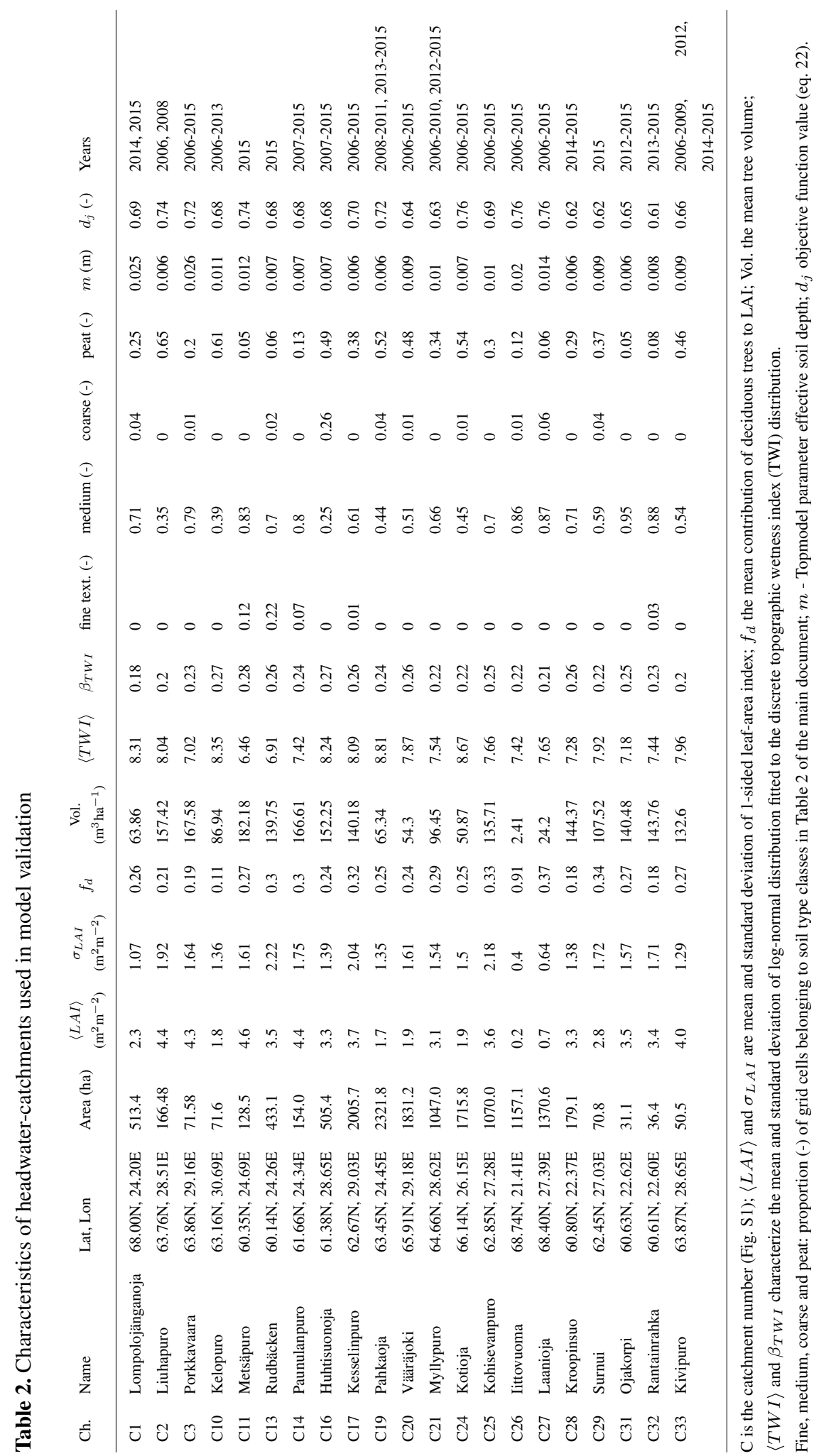




\section{Aerodynamic and surface conductances}

The attenuation of mean wind speed $U$ within the canopy is assumed exponential

$U(z)=U\left(h_{c}\right) \exp ^{\alpha\left(z / h_{c}-1\right)}$,

where $\alpha(-)$ is attenuation coefficient, $h_{c}(\mathrm{~m})$ canopy height and $z$ height above the ground. Neglecting effects of diabatic

5 stability, the wind speed at canopy top $U\left(h_{c}\right)$ can be estimated from wind speed $U_{m}$ at reference height $z_{m}$ (typically 2 or 10 $\mathrm{m})$ using logarithmic wind profile yielding

$U\left(h_{c}\right)=U_{m} \frac{\ln \left[\left(z_{m}-d\right) / z_{o m}\right]}{\ln \left[\left(h_{c}-d\right) / z_{o m}\right]}$

where $d \sim 0.66 h_{c}$ is displacement height and $z_{o m} \sim 0.123 h_{c}$ the roughness height for momentum.

The resistance for turbulent transport in the canopy air space $r_{a}$ (Magnani et al., 1998)

$10 r_{a}=\frac{1}{k_{v}^{2} U_{o}} \ln \left[\left(z_{m}-d\right) / z_{o m}\right] \ln \left[\left(z_{m}-d\right) / z_{o v}\right.$,

where $k_{v} \sim 0.41$ is the von Karman constant and $z_{o v} \sim 0.1 z_{o m}$ the roughness height for water vapor.

Representation for canopy-level quasi-laminar boundary-layer resistance $r_{b}$, assuming uniform leaf-area distribution and exponential wind profile within canopy, has been derived by Choudhury and Monteith (1988)

$r_{b}=\frac{1}{L A I} \beta \sqrt{\frac{w}{U\left(h_{c}\right)} \frac{\alpha}{\left[1-\exp ^{-0.5 \alpha]}\right.}}$,

15 where $w$ is characteristic leaf width (here $0.01 \mathrm{~m}$ ) and proportionality coefficient $\beta \sim 285 \mathrm{~s} \mathrm{~m}^{-1}$ (Campbell and Norman, 1998). The canopy aerodynamic conductance is computed assuming $r_{a}$ and $r_{n}$ act on series

$G_{a, c}=\frac{1}{r_{a}+r_{b}}$.

The surface conductance for sublimation of intercepted snow, $G_{i}$, follows Essery et al. (2003) and Best et al. (2011)

$G_{i}=\frac{3 C_{e} D_{w} S h W}{2 \rho_{i} r^{2}} \sim \frac{C_{e} S h W}{7.68}$,

20 where $S h=1.79+3 U^{0.5}$ is the Sherwood number, $\rho_{i}$ density of ice, $D_{w}$ molecular diffusivity of water vapor in the air, and $r$ the characteristic radius of snow grains $(500 \mu \mathrm{m})$. The exposure coefficient $C_{e}$

$C_{e}=k_{1}\left(\frac{W}{W_{\max }}\right)^{-0.4}$

depends on amount of intercepted snow water $W$ relative to the maximum storage and $k_{1}=0.01$ from Pomeroy et al. (1998).

The forest floor / peatland surface resistance is computed as

$25 r_{a, f}=\frac{1}{k_{v}^{2} U_{g}} \ln \left(z_{g} / z_{o s}\right) \ln \left(z_{g} / z_{\text {osv }}\right)$,

where $U_{g}$ is the wind speed at height $z_{g}$ above ground (from eq. 1), and $z_{o s}$ and $z_{o s v}$ surface roughness heights for momentum and water vapor, respectively. Finally, the forest floor conductance $G_{a, f}=1 / r_{a, f}$. 


\section{Deriving parameter ranges for eq. 4: test against a common gas-exchange model}

In the main paper, eq. 4 provides approach to estimate the canopy conductance $G_{c}$ based on well-established stomatal conductance model, simplified canopy radiation transfer scheme and stand LAI. The stomatal model used is based on Medlyn et al. (2012), who showed that leaf-scale stomatal conductance $\left(g_{s}, \mathrm{~mol} \mathrm{~m}-2 \mathrm{~s}-1\right)$ is related to leaf net photosynthetic rate $(A, \mu \mathrm{mol}$ $\left.5 \mathrm{~m}^{-2} \mathrm{~s}^{-1}\right)$ as

$g_{s} \simeq g_{o}+1.6\left(1+\frac{g_{1}}{\sqrt{D}}\right) \frac{A}{C_{a}}$,

where $C_{a}$ is the atmospheric $\mathrm{CO}_{2}$ mixing ratio $(\mathrm{ppm}), D(\mathrm{kPa})$ is vapor pressure deficit, $g_{o}$ residual (or cuticular) conductance and $g_{1}$ a species-specific parameter that depends on plant water use strategy. Noting that $g_{o} \ll g_{s}$ (Medlyn et al., 2012) and representing photosynthetic light response by saturating hyperbola (Saugier and Katerji, 1991), eq. (9) can be approximated as

$g_{s}=1.6\left(1+\frac{g_{1}}{\sqrt{D}}\right) \frac{A_{\max }}{C_{a}} \frac{P A R}{P A R+b} C_{a i r}$,

where $A_{\max }\left(\mu \mathrm{mol} \mathrm{m}^{-2} \mathrm{~s}^{-1}\right)$ is the light-saturated photosynthesis rate, $b\left(\mathrm{~W} \mathrm{~m}^{-2}\right)$ the half-saturation value of photosynthetically active radiation (PAR), and molar density of air $C_{\text {air }}\left(\mathrm{mol} \mathrm{m}^{-3}\right)$ converts units of $g_{s}$ to $\mathrm{m} \mathrm{s}^{-1}$. The eq. 10 suggests that $g_{s}$ in a reference conditions (fixed $\mathrm{D}$ and $\mathrm{CO}_{2}$ ) is constrained by plant water use and photosynthetic traits. There are readily measurable by leaf gas-exchange techniques, and widely available in literature and in plant trait databases such as TRY (Kattge et al., 2011).

For sensitivity analysis (Sect. 2.5), we determined plausible parameter ranges (Table 3) using literature, shoot gas-exchange measurements at FIHy and predictions of common leaf photosynthesis model (Farquhar et al., 1980b) model coupled with eq. 9. For Scots pine, $g_{1}$ was shown to vary between 1.9 and 2.3 for different shoots measured at FIHy (Launiainen et al., 2015), while $g_{1}$ was 3.5 - 4.0 for deciduous Aspen and Birch leaves at the same site (unpublished data). These fall well within the values from global synthesis, giving mean $g_{1} 2.35$ for evergreen gymnosperm and 4.67 for deciduous angiosperm tree species (boreal biome mean $g_{1} 2.2$ ) (Lin et al., 2015). The $A_{\max }$ and $b$ can be derived from shoot gas-exchange measurements, or as here by using common leaf gas-exchange model (Farquhar et al., 1980b) with parameter values characteristic for boreal plants. Fig. 3 hows photosynthetic light response curves for combinations of parameter values (at reference temperature $25^{\circ} \mathrm{C}$ ):

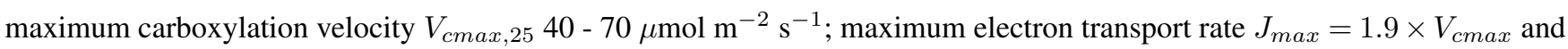
dark respiration rate $r_{d}=0.02 \times V_{c \max }$. For the specific version of Farquhar -model used, and its other 'generic' parameters see Launiainen et al. (2015).

The plausible values for $A_{\max }$ and $b$ can be now approximated by fitting empirical light response $A_{\max } Q_{p} /\left(Q_{p}+b\right)$ to leaf gas-exchagne model predictions. Further, as $V_{c \max }$ and $A_{\max }$ are strongly related to leaf $\mathrm{N}$ (Kattge et al., 2009), using site fertility class as a proxy for $A_{\max }$ could later provide a way to infuse site type effect into spatial predictions of transpiration.

The upscaling from $g_{s}$ to $G_{c}$ by the proposed scheme (eq. 4 in the main paper), and the leaf gas-exchange model predictions are compared in 4 . The $G_{c}$ in X-axis corresponds to case $V_{c \max }=55 \mu \mathrm{mol} \mathrm{m}^{-2} \mathrm{~s}^{-1}$ and $g_{1}=2.5$ in Fig. 3 and is computed 
as follows: First, a canopy with LAI $=4.0 \mathrm{~m}^{2} \mathrm{~m}^{-2}$ is divided into 100 layers and absorbed $Q_{p}$ (per unit leaf area) at each layer computed assuming attenuation of $Q_{p}$ exponential with attenuation coefficient $k_{p}=0.6$ ( $\mathrm{T}$ and $D$ taken constant with height). Then, $g_{s}$ for each layer is computed by the leaf gas-exchange model using local $Q_{p}$, and integrated with respect to LAI to yield $G_{c}$. The parameters for eq.4 are inferred from the leaf-scale light-response (Fig. 3) as $A_{\max }=11.6 \mu \mathrm{mol} \mathrm{m}^{-2}$ and $b=60$

$5 \mathrm{Wm}^{-2}$. The forcing data $\left(Q_{p}, D\right.$ and $\left.\mathrm{CO}_{2}\right)$ were taken from $1 / 2 \mathrm{~h}$ average values in July-August 2005 at FIHy site. The results show reasonably good correspondence at the sub-daily timescale. The applicability of eq. 4 at daily timescale is then indirectly explored in the main manuscript by comparison against daily dry-canopy ET measurements from ten boreal FluxNet sites.
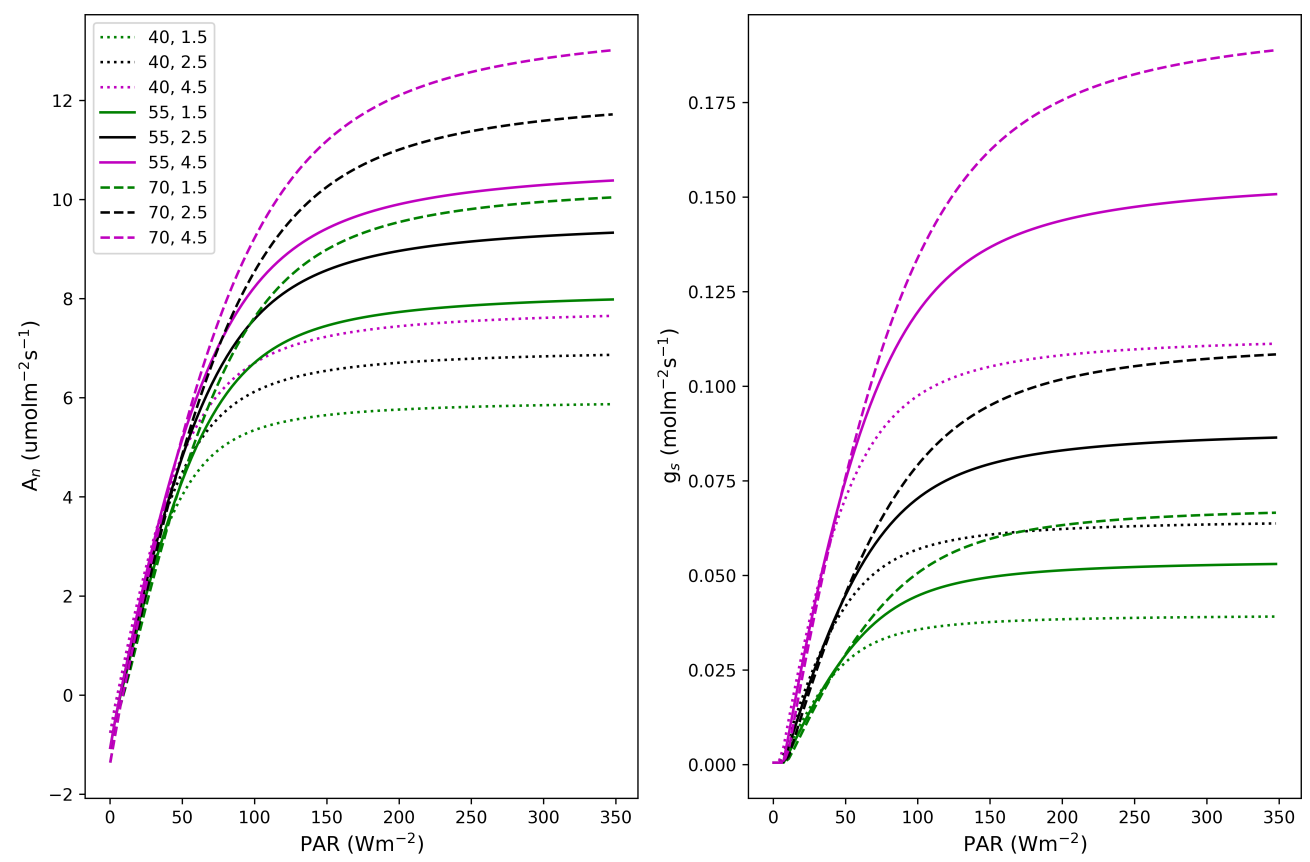

Figure 3. Photosynthetic light response and stomatal conductance predicted by a common leaf gas-exchange model for different parameter combinations. The legend gives values of $V_{c \max }$ and $g_{1}$ for each curve. See text for details. 


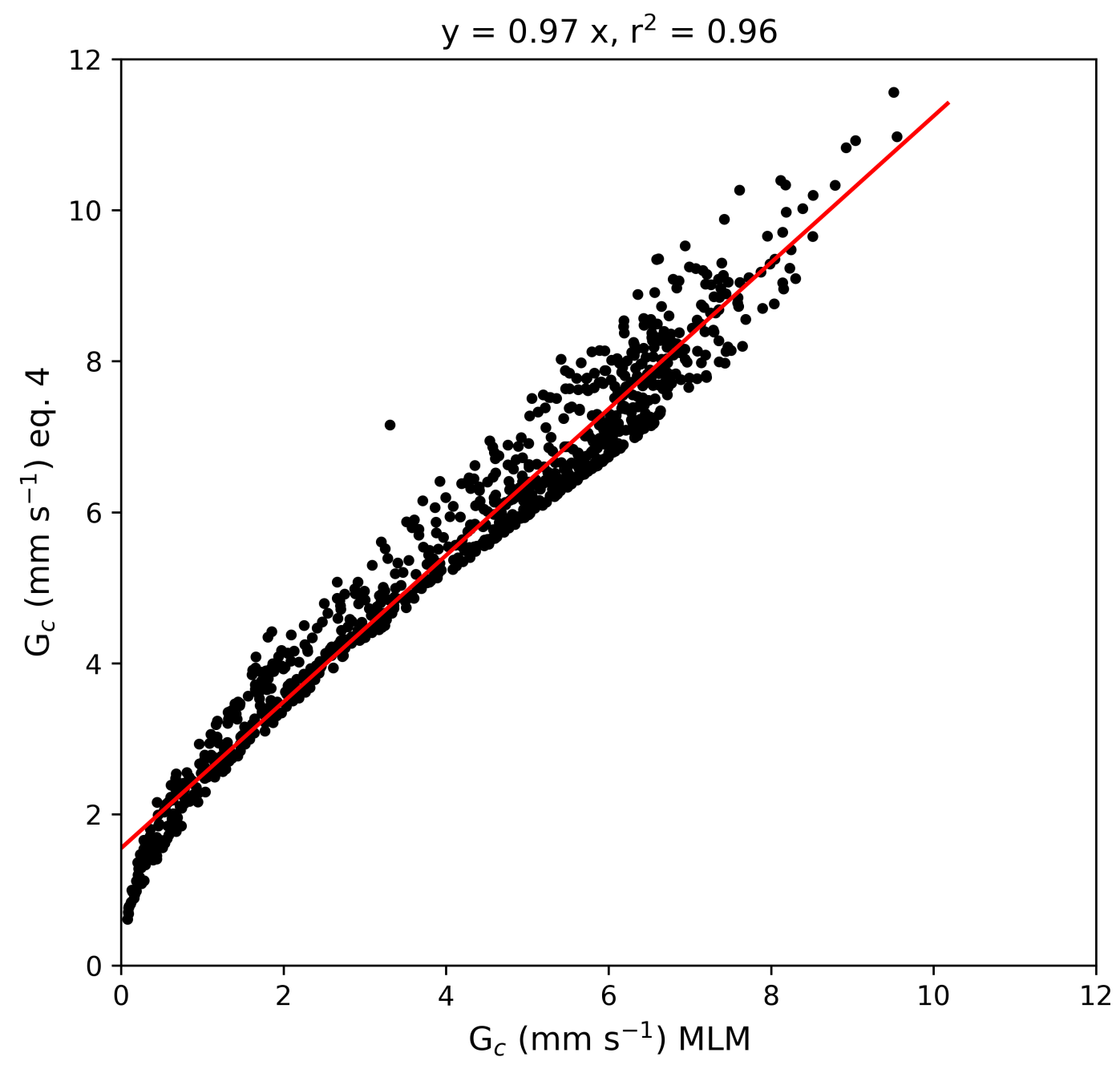

Figure 4. Canopy conductance $G_{c}$ predicted by a leaf gas-exchange model combined with exponential attenuation of radiation (x-axis) and by the proposed simplification (eq. 4 in the main manuscript, y-axis). The canopy LAI $=4.0 \mathrm{~m}^{2} \mathrm{~m}^{-2}$ and the parameters of gas-exchange model correspond to case $V_{c \max }=55 \mu \mathrm{mol} \mathrm{m}^{-2} \mathrm{~s}^{-1}$ and $g_{1}=2.5 \mathrm{in} \mathrm{Fig.} \mathrm{3,} \mathrm{while} \mathrm{those} \mathrm{in} \mathrm{eq.} 4$ uses $A_{\max }$ and $b$ inferred by fitting the light response $A_{\max } Q_{p} /\left(Q_{p}+b\right)$ to that particular case in Fig. 3. The points show $1 / 2 \mathrm{~h}$ predictions and the red line is linear-least squares regression. 


\section{Snow model}

Snowpack at the forest floor is described through snow water equivalent (SWE), which consists on solid ( $\left.\mathrm{SWE}_{i}\right)$ and liquid phases $\left(\mathrm{SWE}_{l}\right)(\mathrm{mm})$. Their respective mass balances are computed as

$\frac{\Delta S W E_{i}}{\Delta t}=f_{s}\left(T_{f}+U_{s}\right)+F-M$

$5 \frac{\Delta S W E_{i}}{\Delta t}=\left(1-f_{s}\right)\left(T_{f}+U_{s}\right)-F+M$,

where $f_{s}$ is temperature-dependent fraction of precipitation falling as snow, $T_{f}$ and $U_{s}$ throughfall and snow unloading rates, respectively. The snowmelt $M$ and liquid water re-freezing $F\left(\mathrm{~mm} \mathrm{~d}^{-1}\right)$ are estimated based on degree-day approach

$$
\begin{aligned}
M & =\min \left(S W E_{i}, K_{m} T_{a}\right), T_{a}<0.0^{\circ} C \\
F & =\min \left(S W E_{l}, K_{f} T_{a}\right), T_{a}>0.0^{\circ} C,
\end{aligned}
$$

10 where $K_{m}\left(\mathrm{~mm} \mathrm{~d}^{-1}{ }^{\circ} \mathrm{C}^{-1}\right)$ is melting coefficient and freezing coefficient $K_{f} \sim 0.3 \mathrm{~mm} \mathrm{~d}^{-1}{ }^{\circ} \mathrm{C}^{-1}$ is assumed independent of stand characteristics. The snowpack can retain only a certain fraction of liquid water, and thus $\mathrm{SWE}_{l}$ is constrained to $\leq r S W E_{i}$, where $r \sim 0.05$. The excess liquid water from the snowpack is routed to soil sub-model (Bucket) as potential infiltration $I_{f, p}$. In snowfree conditions $I_{f, p}=T_{f}$. 


\section{References}

Best, M., Pryor, M., Clark, D., Rooney, G., Essery, R., Ménard, C., Edwards, J., Hendry, M., Porson, A., Gedney, N., et al.: The Joint UK Land Environment Simulator (JULES), model description-Part 1: energy and water fluxes, Geoscientific Model Development, 4, 677-699, 2011.

5 Bittelli, M., Campbell, G. S., and Tomei, F.: Soil Physics with Python: Transport in the Soil-Plant-Atmosphere System, OUP Oxford, 2015. Campbell, G. S. and Norman, J. M.: Introduction to Environmental Biophysics, Springer, 2nd edn., 1998.

Choudhury, B. J. and Monteith, J.: A four-layer model for the heat budget of homogeneous land surfaces, Quarterly Journal of the Royal Meteorological Society, 114, 373-398, 1988.

Essery, R., Pomeroy, J., Parviainen, J., and Storck, P.: Sublimation of snow from coniferous forests in a climate model, Journal of Climate, 16, 1855-1864, 2003.

Farquhar, G. D., Caemmerer, S. V., and Berry, J. A.: A biochemical model for photosynthetic CO2 assimilation in leaves of C3 species, Planta, 149, 78-90, 1980a.

Farquhar, G. v., von Caemmerer, S. v., and Berry, J.: A biochemical model of photosynthetic CO2 assimilation in leaves of C3 species, Planta, 149, 78-90, 1980b.

15 Kattge, J., Knorr, W., Raddatz, T., and Wirth, C.: Quantifying photosynthetic capacity and its relationship to leaf nitrogen content for globalscale terrestrial biosphere models, Global Change Biology, 15, 976-991, 2009.

Kattge, J., Diaz, S., Lavorel, S., Prentice, I. C., Leadley, P., Bönisch, G., Garnier, E., Westoby, M., Reich, P. B., Wright, I. J., et al.: TRY-a global database of plant traits, Global Change biology, 17, 2905-2935, 2011.

Launiainen, S., Katul, G. G., Lauren, A., and Kolari, P.: Coupling boreal forest CO2, H2O and energy flows by a vertically structured forest canopy - Soil model with separate bryophyte layer, Ecological Modelling, 312, 385-405, 2015.

Lin, Y.-S., Medlyn, B. E., Duursma, R. A., Prentice, I. C., Wang, H., Baig, S., Eamus, D., de Dios, V. R., Mitchell, P., Ellsworth, D. S., et al.: Optimal stomatal behaviour around the world, Nature Climate Change, 5, 459, 2015.

Magnani, F., Leonardi, S., Tognetti, R., Grace, J., and Borghetti, M.: Modelling the surface conductance of a broad-leaf canopy: effects of partial decoupling from the atmosphere, Plant, Cell \& Environment, 21, 867-879, 1998.

25 Medlyn, B. E., Duursma, R. A., Eamus, D., et al.: Reconciling the optimal and empirical approaches to modelling stomatal conductance, Global Change Biology, 18, 3476-3476, 2012.

Pomeroy, J., Parviainen, J., Hedstrom, N., and Gray, D.: Coupled modelling of forest snow interception and sublimation, Hydrological Processes, 12, 2317-2337, 1998.

Saugier, B. and Katerji, N.: Some plant factors controlling evapotranspiration, Agricultural and Forest Meteorology, 54, 263-277, 1991. 